\title{
Análise dos agentes estressores e a expressão do estresse entre trabalhadores portuários avulsos ${ }^{1}$
}

\author{
Analysis of stressors agents and stress \\ expression among temporary \\ dock workers
}

\author{
Pedro Quaresma CARDOSO ${ }^{1}$ \\ Ricardo da Costa PADOVANI ${ }^{2}$ \\ Adriana Marcassa TUCCI ${ }^{2}$
}

\section{Resumo}

Mudanças decorrentes de processos de reorganização nos locais de trabalho têm sido associadas a aumento de estresse entre trabalhadores. O objetivo do estudo foi investigar a percepção do trabalhador portuário acerca da presença de estresse no trabalho no Porto de Santos, São Paulo. Trata-se de um estudo de natureza qualitativa, cujos dados foram colhidos por meio de entrevistas semiestruturadas e do Inventário de Sintomas de Estresse para Adultos de Lipp. Foram entrevistados 17 trabalhadores portuários avulsos, dos quais 10 apresentaram estresse. Na percepção dos participantes, a atual organização do trabalho parece promover situações aversivas que favorecem o aparecimento e manutenção do estresse. Parece haver relação entre estresse e presença constante de sobrecarga física, exposição a ambientes hostis, má relação com o empregador, falta de equidade na distribuição do trabalho, e diminuição da remuneração, do número de trabalhadores por terno, da autonomia no trabalho, e da possibilidade de convívio familiar e lazer.

Palavras-chave: Estresse; Percepção social; Saúde mental; Turno de trabalho.

\begin{abstract}
Changes arising from the reorganization of workplaces have been associated with increased stress among workers. The aim of this study was to investigate the perceptions of port workers about the presence of stress due to the

$\nabla \nabla \nabla v$

1 Psicólogo. Santos, SP, Brasil.

2 Universidade Federal de São Paulo, Departamento de Saúde, Educação e Sociedade, Programa de Pós-Graduação Interdisciplinar em Ciências da Saúde. Av. D. Ana Costa, 95, Vila Mathias, 11060-001, Santos, SP, Brasil. Correspondência para/Correpondence to: A.M. TUCCI. E-mail: <atucci@unifesp.br>.

Artigo elaborado a partir da dissertação de P.Q. CARDOSO, intitulada "Processo de modernização portuaíria em Santos e as implicações na saúde mental dos trabalhadores: estresse, uso abusivo de sustâncias psicoativas e violência". Universidade Federal de São Paulo, 2012.

Apoio: Coordenação de Aperfeiçoamento de Pessoal de Nível Superior.
\end{abstract}


process of modernization in the port of Santos. The study had a qualitative design and the data was collected by means of semi-structured interviews and Lipp's Inventory of Stress Symptoms. Seventeen temporary port workers were interviewed, 10 of whom had stress. In the perception of the worker, the current work organization seems to promote adverse situations that favor the occurrence and maintenance of stress. There seems to be a relationship between stress and the constant presence of physical overload, exposure to hostile environments, poor relationships with employers, a lack of equitable distribution of work, and reductions in the number of workers, salaries, autonomy at work, and the possibility of family life and leisure time.

Keyworks: Stress; Social perception; Mental health; Workday shifts.

As mudanças econômicas e tecnológicas, fato marcante com o advento da globalização nas últimas décadas, alteraram substancialmente o ambiente e as relações de trabalho. Tal contexto exerce grande impacto na vida do trabalhador, seja em razão dos benefícios alcançados, seja em virtude das adversidades impostas por essa nova dinâmica, tornando-o mais suscetível ao desenvolvimento de sintomas significativos de estresse (Dextras-Gauthier, Marchand, \& Haines, 2012; Leka, Griffiths, \& Cox, 2005; Sardá Jr., Legal, \& Jablonski Jr., 2008). Está bem estabelecido na literatura que o trabalho e o local onde ele se realiza são importantes determinantes sociais da saúde (Almondes \& Araújo, 2009; Barbosa \& Borges, 2011; Dextras-Gauthier et al., 2012; Kerry, Roman, Critchley, \& Clare, 2012).

Em virtude da fluidez comercial das atividades dos portos, seus trabalhadores são constantemente desafiados a adaptar-se às novas demandas. Aguiar, Junqueira e Freddo (2006) destacaram que o processo de modernização portuária no Brasil visou à inserção do País em uma economia globalizada, por meio do aumento da produtividade, da maior agilidade no embarque e desembarque e da diminuição de custos operacionais dos serviços portuários. Nesse contexto, o Porto de Santos, o maior da América Latina, é constantemente instado a remodelar suas formas de organização laboral, de modo que tal análise merece atenção.

Os mecanismos do processo de quebra do monopólio privado foram regulamentados pela Lei n 8.630/93 (Brasil, 1993) - conhecida como Lei de Modernização dos Portos -, e desencadearam mudanças na estrutura, dinâmica e cultura do trabalho no Porto de Santos (Gomes \& Junqueira, 2008; Machin, Couto, \& Rossi, 2009). Gitahy (1992) afirma

508 que, antes dessas mudanças, a reserva de mercado no Porto de Santos garantia acesso e sindicalização de familiares de estivadores. Adicionalmente, um fator que merece destaque diz respeito à natureza sazonal e ocasional desse trabalho, sujeito a períodos de safras e a exposição às condições climáticas, exigindo que o trabalhador esteja nas proximidades do cais, permanentemente disponível e sob condições nem sempre favoráveis.

No período anterior à lei de modernização dos portos, tal situação favoreceu, no caso santista, a constituição de uma cultura urbana marcada por sólidas redes de comunicação e por verdadeiras linhagens de famílias portuárias (Diéguez, 2007; Silva, 2003). Assim, o trabalho era realizado por grupos marcados por relações de parentesco ou de afetividade.

Com o processo de modernização e a nova gestão do trabalho portuário, entre outras mudanças, ocorreu o fim das categorias profissionais e a criação da figura do Trabalhador Portuário Avulso (TPA) vinculado ao Órgão Gestor de Mão de Obra (OGMO). Hoje, cabe a este órgão intermediar o trabalho do TPA, sem vínculo empregatício e em regime de escala de rodízio, para exercer qualquer função portuária. Esse novo modelo trouxe ainda novas formas de gestão do trabalho portuário, como a intensificação da produtividade e do volume de trabalho, a extinção de algumas funções e a exigência de maior qualificação (Machin et al., 2009). No mesmo sentido, a literatura deixa evidente o quanto as características da dinâmica e cultura organizacional determinam a relação trabalho-trabalhador e, consequentemente, o processo de adoecimento psíquico (Dextras-Gauthier et al., 2012). Nesse cenário, infere-se que a ruptura de uma cultura de trabalho historicamente estabelecida acarretará grande repercussão na relação trabalho-trabalhador no Porto de Santos. 
Cada trabalhador recebe uma numeração individual, a partir da qual serão formados grupos (ternos), conforme a função executada no porto. Há diferentes locais de seleção e recrutamento dos trabalhadores portuários avulsos, que funcionam em quatro turnos (6h:45mim, 12h:45mim, $18 \mathrm{~h}: 45 \mathrm{mim}$ e 17h:30mim), nos quais os trabalhadores são escalados e recrutados, cobrindo as $24 \mathrm{~h}$ de funcionamento do porto. Essa escala obedece a um rodízio, de acordo com a numeração do TPA, que pode trabalhar em qualquer horário e em qualquer sistema de rodízio. Os trabalhadores são solicitados conforme a movimentação do porto e a quantidade estipulada por cada empresa. Por essas razões, pode-se aferir que a rotina dos TPA depende de vários fatores, como a numeração do cadastro ou registro, a presença de navios atracados para embarque e desembarque (movimentação do porto), a quantidade de trabalhadores requisitados pela empresa para o serviço, as condições climáticas, entre outros. Todos esses fatores contribuem para que os TPA não tenham uma rotina fixa de trabalho, como em um emprego tradicional.

A literatura tem apontado que mudanças nas escalas de trabalho se apresentam como favoráveis ao aparecimento de estresse e outros sintomas psíquicos (Almondes \& Araújo, 2009; Barbosa \& Borges, 2011; Kerry et al., 2012). Em estudo relativo às condições de trabalho dos TPA do Porto de Santos, Machin et al. (2009) detectaram que as principais dificuldades geradas pela Lei de Modernização decorreram de mudanças na composição das equipes (ternos), como a diminuição do número de integrantes e a falta de entrosamento entre eles, conforme ocorria anteriormente. Mencionaram que, embora a modernização tenha reduzido o desgaste físico, os trabalhadores referiram haver considerável desgaste mental no trabalho, em razão das condições precárias de muitos navios, máquinas e equipamentos.

Os riscos inerentes à saúde e à segurança individual e coletiva nas atividades desenvolvidas pelos TPA analisados no estudo de Soares et al. (2008), no porto do Rio Grande do Sul (RS), apontaram a drogadição no trabalho (álcool, maconha, cocaína e crack), a constante possibilidade de queda de objetos suspensos, a presença de ruídos e a exposição a intempéries, bem como as próprias características das relações interpessoais estabelecidas entre os membros da equipe de trabalho (ternos).

O cenário exposto deixa evidente a expressiva diversidade de agentes estressores de natureza física (por exemplo, a exposição às condições climáticas e ao ruído intenso) e, principalmente, de natureza emocional (aumento da cobrança e da tensão, deterioração das relações de trabalho e supressão das escolhas da equipe, antes fundamentadas nas relações afetivas) presentes no ambiente de trabalho portuário, favoráveis ao agravamento do estresse e do comprometimento da saúde do trabalhador. Portanto, a diversidade de agentes estressores aos quais os TPA estão expostos demonstra a relevância de estudos que venham investigar as características do trabalho portuário, bem como suas consequências para a saúde, a partir do entendimento das percepções do trabalhador quanto às situações estressantes que possam gerar sofrimento psíquico. O estresse decorrente da atividade profissional se manifesta quando o indivíduo avalia as demandas do trabalho como excessivas diante dos recursos de enfrentamento de que dispõe (Lipp, 2001; Sardá Jr. et al., 2004; Sprung \& Jex, 2012).

O presente estudo partiu da hipótese de que agentes estressores no ambiente de trabalho portuário favoreceriam a emergência de sintomas de estresse, prejudicando de maneira significativa a qualidade de vida e as relações interpessoais desses profissionais.

Cabe destacar que é extremamente reduzido o número de estudos acerca do trabalhador portuário, não tendo sido encontrado nenhum artigo que abordasse a expressão do estresse nessa população. Os estudos desenvolvidos por Soares et al. (2008) e Machin et al. (2009) permitiram identificar os agentes estressores, mas a investigação dos mecanismos cognitivos e reações emocionais relacionados a tal exposição não constituíram os objetivos dos autores, reforçando a importância de sua investigação.

O estresse, no presente estudo, é entendido como um conjunto de reações psicofisiológicas e 
comportamentais complexas, cuja função é adaptar o organismo a uma situação que ameace a homeostase interna, ou seja, o estresse não necessariamente é patológico. O desequilíbrio ocorre quando o indivíduo necessita responder a alguma demanda que ultrapasse sua capacidade adaptativa. Nesse sentido, o estresse pode ser concebido como uma resposta necessária à manutenção da vida (Kyrou \& Tsigos, 2009; Lipp, 2000, 2003; Sardá Jr. et al., 2004). Estudiosos alertaram que não é só o tipo de agente estressor que determina se será desenvolvido um quadro de estresse patológico, mas que este depende também da avaliação cognitiva que o indivíduo faz do evento (Lazarus \& Folkman, 1984; Lipp, 2001, 2003). Tal constatação deixa evidente o impacto das características idiossincráticas nas estratégias de coping e, consequentemente, na determinação do estresse (Antoniazzi, Dell'Aglio, \& Bandeira, 1998; Lazarus, 1999; Lazarus \& Folkman, 1984).

É consenso na literatura que o estresse, quando crônico ou excessivo, favorece a emergência de uma série de prejuízos para saúde física e mental (Lazarus, 1999; Lipp, 2003; Sardá Jr. et al., 2008; Kyrou \& Tsigos, 2009). Todavia, quando em doses moderadas e sob o ponto de vista da organização do trabalho, o estresse pode implicar aumento de motivação e produtividade. No entanto, quando desproporcional em termos de frequência e intensidade, pode gerar excesso de atrasos e faltas, aumento de licenças médicas, alta rotatividade, acidentes de trabalho, queda na produtividade, desempenho irregular e dificuldades interpessoais (Lipp, 2003).

Buscando ampliar o entendimento do trabalhador portuário avulso, o presente estudo buscou avaliar a percepção dos agentes estressores no ambiente portuário, na perspectiva desse profissional no Porto de Santos. Adicionalmente, buscou investigar a relação de tais contingências na expressão do estresse.

\section{Método}

Trata-se de um estudo transversal, explora510 tório, descritivo, de natureza quantitativa e quali- tativa, na área de abrangência do Porto de Santos, englobando as categorias de estivador, capataz, conferente e vigilante de embarcação. A pesquisa foi aprovada pelo Comitê de Ética em Pesquisa da Universidade Federal de São Paulo, sob no 1268/10, sendo conduzida segundo os parâmetros da Resolução 196/96 do Conselho Nacional de Saúde.

Foi realizada tentativa de contato telefônico com 105 trabalhadores portuários avulsos, dos quais 40 foram localizados e 17 aceitaram participar do estudo. Os critérios de inclusão dos participantes foram: ser integrante das principais categorias funcionais na atividade portuária e trabalhar como TPA no mínimo há 10 anos. Esse tempo de trabalho foi estabelecido como forma de recrutar participantes com experiência sólida e significativa no trabalho portuário, evitando-se a inclusão de sujeitos com menor conhecimento da dinâmica dos serviços.

\section{Participantes}

Foram entrevistados 17 trabalhadores portuários avulsos do Porto de Santos, pertencentes às categorias de estivador $(n=11)$, trabalhador da capatazia $(n=3)$, conferente $(n=2)$ e vigilante de embarcação $(n=1)$.

\section{Instrumentos}

\section{Roteiro de entrevista semiestruturada}

O presente estudo baseou-se em uma metodologia de natureza qualitativa. Foi empregado um roteiro de entrevista semiestruturada, elaborado pelos autores, abordando as seguintes temáticas: relação entre estresse e trabalho; relação entre esforço físico e saúde; cansaço físico e mental decorrente do trabalho; relação entre sobrecarga de trabalho e saúde; e forma de utilização de tempo livre.

\section{Inventário de Sintomas de Stress para Adultos} (ISSL)

O instrumento é constituído por uma lista de sintomas físicos e psicológicos que permitem 
identificar se a pessoa tem estresse, em que fase do processo se encontra (alerta, resistência, quase-exaustão e exaustão) e se sua sintomatologia é mais típica da dimensão física ou psicológica. Estrutura-se em três quadros, referentes às quatro fases de estresse propostas pela autora: o Quadro 1 (Q1) avalia a fase de alerta; o Quadro 2 (Q2), a fase de resistência e a fase de quase-exaustão; o Quadro 3 (Q3), a fase de exaustão, que permite o diagnóstico de estresse. O respondente é solicitado a indicar se tem apresentado o sintoma de estresse especificado em cada quadro, no período de 24 horas (Q1), 1 semana (Q2) e 1 mês (Q3).

\section{Procedimentos}

As entrevistas, com duração média de 90 minutos, foram realizadas individualmente, em salas nas quais foram garantidos o sigilo e os cuidados éticos. As entrevistas, realizadas no período de maio a novembro de 2011, foram gravadas e depois transcritas e analisadas.

Para análise dos dados, foi realizada leitura flutuante do material coletado nas entrevistas, buscando, tanto no discurso manifesto quanto no latente, os sentidos que a pesquisa procurou investigar. As entrevistas foram analisadas a partir da identificação de temas específicos, considerados relevantes para a compreensão dos significados do objeto estudado (Minayo, 1992). A análise quantitativa envolveu a análise do escore do ISSL (Lipp, 2000).

A Tabela 1 apresenta a caracterização dos TPA. O tempo médio de trabalho portuário foi de 21 anos. Quanto aos rendimentos financeiros, a renda mensal variou de 1 a 9 salários-mínimos. 0 grupo investigado se constituiu de homens, com idade superior a 40 anos, com predominância de casados e ensino fundamental completo. Nota-se que quatro participantes tinham ensino superior completo e um havia concluído a pós-graduação.

\section{Resultados e Discussão}

O trabalho no porto é historicamente relacionado a uma atividade desgastante, por promover
Tabela 1

Caracterização dos TPA do Porto de Santos (SP)

\begin{tabular}{lc}
\hline Características & Idade \\
\hline Faixa Etária & 40 - 66 anos \\
Estado Civil & 11 \\
Casado/união estável & 2 \\
Divorciado & 4 \\
Solteiro & \\
Escolaridade & 1 \\
Ensino Fundamental Incompleto & 4 \\
Ensino Fundamental Completo & 8 \\
Ensino Médio Completo & 3 \\
Superior Completo & 1 \\
Pós-Graduação & 21 anos \\
Tempo médio de trabalho portuário & 1 - $9 \mathrm{SM}^{*}$ \\
Renda Mensal &
\end{tabular}

Nota: *SM: Salário-Mínimo.

sobrecarga física e emocional, além da exposição a ambientes hostis e de risco à saúde do trabalhador (Gitahy, 1992; Gonçalves \& Nunes, 2008).

Segundo relato dos participantes, no Porto de Santos as atividades são desenvolvidas em condições de trabalho extremas, tais como: contato com produtos químicos no ar, poeira, exposição a condições climáticas contrastantes em um mesmo dia, altura, exposição ao balanço do mar, locais com pouca ventilação e odores fortes. Tais relatos descrevem um ambiente físico insalubre, com alto risco de acidentes e diretamente relacionado à produção de altos níveis de estresse físico e mental entre os trabalhadores.

Entrevistador: "E como os esforços podem prejudicar a saúde?".

Participante 12: "Todo o trabalho de turno, por rodízio, termina afetando [a saúde]. Só quem trabalha no turno da 1 da madruga até as 7 da manhã, debaixo de poeira e driblando caminhão, sabe o que é isso".

Assim, os trabalhadores descreveram o trabalho como uma atividade de alto risco, pontuando a presença de acidentes de natureza grave, como por exemplo, amputação e morte, corroborando os achados de Soares et al. (2008) quanto aos riscos ocupacionais à saúde do trabalho no ambiente portuário no Brasil. O relato do Participante 12 (P12) 
deixa evidente a gravidade dos riscos inerentes ao trabalhado portuário:

"Ou você mutila braço, perna, mão, ou você morre. Não tem acidente assim de quebrar. Fica passando o aparelho em cima do mar com você... dá uma tremedeira que quando você sai do trabalho, quando você desce no chão, você tá mole, fica desanimado. A descarga de adrenalina te deixa assim e você vai embora. Pra morrer, é assim" (P12).

O alto nível de estresse, decorrente da sobrecarga de trabalho e da exposição a um ambiente hostil, apresentou-se como uma questão central entre os trabalhadores entrevistados. Entretanto, os relatos revelaram haver uma somatória entre o desgaste físico, intrínseco da própria atividade portuária, e o desgaste mental, produzido pela organização do trabalho, principalmente quanto a sazonalidade, distribuição, remuneração e relação com os empregadores. Esse dado dialoga com aqueles obtidos no estudo realizado por Santos e Cardoso (2010) com profissionais de saúde mental. indicando as características da organização do trabalho como fatores frequentemente relacionados à percepção de estar sob estresse excessivo, bem como com a discussão de Dextras-Gauthier et al. (2012) referente às característica da dinâmica da cultura organizacional e sua relação com a saúde mental do trabalhador.

O desgaste de natureza mental foi considerado, pela maioria dos entrevistados, como o principal determinante da exacerbação do estresse. A organização e a dinâmica de seleção para o trabalho, a presença de conflitos (OGMO/trabalhadores, operadoras portuárias/trabalhadores) e a necessidade de fazer mais de uma jornada, quando há trabalho disponível, dimensionam as características dos agentes estressores presentes no trabalho portuário. O relato do participante 15 ilustra tal situação: "Mais desgaste assim no trabalho, não é físico, é mais mental... é essa ansiedade de querer ganhar, de querer produzir...".

As queixas mais frequentes dos participantes referiram-se à inconstância de trabalho e à organização da seleção. Os relatos ilustram a questão: 512 "... uma selvageria no ponto de escala, um que- rendo trabalhar mais que o outro; não tem quem não se estresse com a escala" (P12); "É naquele pensamento de querer agilizar para produzir que acontecem acidentes. Um subiu no navio, pelo contêiner, e caiu, morreu" (P5).

Apesar de o Órgão Gestor de Mão de Obra considerar que a escala dos trabalhadores realizada atualmente é mais equitativa, por apresentar maiores oportunidades de trabalho graças ao sistema de rodízio (Gonçalves \& Nunes, 2008), os TPA revelaram que ainda existem muitas desigualdades no porto, principalmente em relação às oportunidades de trabalho e à remuneração.

O estresse crônico e as características do trabalho portuário (sobrecarga, exigência de atenção e concentração) se apresentam como importantes fatores de risco para a ocorrência de acidentes de trabalho. Esses aspectos foram apontados no estudo de Qureshi, Shabbir, Hafeez, \& Ahmad, (2010), em que médicos em jornadas de 24 horas, comparados aos que realizavam jornadas de 6 horas, apresentaram diminuição significativa em habilidades cognitivas e comportamentais, como concentração e memória, conduzindo a maior risco de acidentes de trabalho e erros. Almondes e Araújo (2009) apontaram também que trabalhadores de turno da indústria petrolífera apresentavam ansiedade significativamente mais alta quando comparados aos que realizavam seu trabalho em jornada diurna fixa. Tais considerações reforçam a necessidade de aprofundamento das reflexões a respeito da saúde do trabalhador portuário, tema ainda pouco explorado na literatura. O impacto do trabalho para a saúde e bem-estar do trabalhador também foi apontado em dois estudos de revisão sistemática (Kerry et al., 2012; Sprung \& Jex, 2012).

O impacto dos agentes estressores no aumento dos riscos de acidente de trabalho fica evidente no relato dos participantes: "Estresse aumenta o número de acidentes, sim. Se tu tiver trabalhando aqui direto no estresse, ele vai tirar teu reflexo. Deixa a pessoa desligada. Nesse segundo de desligamento é quando acontece um acidente" (P5); "Você trabalhando 12h, 24h, 48h, é lógico que o seu corpo não vai aguentar" (P6). 
Os relatos de acidentes de trabalho foram frequentes, evidenciando o risco ocupacional do trabalho portuário. Tal situação pode ser ilustrada a partir do relato abaixo, no qual aparece o cotidiano do trabalhador que desenvolve suas atividades no interior dos porões ou nos convés dos navios. Esse trabalho é realizado sobre pilhas de contêineres, na altura de 15 a 25 m acima do nível do mar, muitas vezes durante a madrugada e com iluminação artificial, exposto a intempéries climáticas, compensando-se o balanço do mar com o equilíbrio do próprio corpo. Foi ainda mencionada a necessidade de uma refinada interação com os outros TPA, a tripulação e os funcionários das operadoras portuárias, para que o trabalho ocorra de maneira correta, como se vê neste relato:

"Eu já vi gente caindo do contêiner porque, às vezes, você está numa pilha de contêiner. O cara ali, ele faz o sinal, o guincheiro interpretou errado, aí você tá do lado de um contêiner e ele tá chegando com outro contêiner e ali pra baixo é o mar. Tem que pular, tem que ir pela frente e pular... ou ficar, como muitos ficam às vezes, o cara se joga, se abaixa, arreia, mói, vira pastel e eu já vi muitos se jogando, pô! Se jogar às 3 h30 min da manhã, 4h da manhã, no inverno, de jaqueta, bota, capacete, tudo, e se jogar no mar naquela altura ali. Às vezes é fatal" (P12).

O convívio com os próprios colegas de trabalho também tem sido relacionado ao aumento dos níveis de estresse. O estudo de Santos e Cardoso (2010) demonstrou que as condições de trabalho como estrutura física precária e dificuldades na execução do trabalho em equipe por falta de confiança nos colegas -, foram os fatores mais frequentemente associados à percepção de estresse entre profissionais de saúde. No caso dos TPA do Porto de Santos, as situações de conflito relatadas ocorriam basicamente em dois momentos: na seleção e na realização do trabalho. Os conflitos durante a seleção foram os mais referidos nas entrevistas e, segundo os TPA, ocorriam principalmente por desconfiança de que o colega estaria de alguma forma tentando obter vantagem na seleção: "a gente lá não pode ser bobo, se não as pessoas montam em cima. Tem que impor, e fazer que as pessoas te respeitem" (P8).

$$
\begin{aligned}
& \text { Entrevistador: "de que forma a sobrecarga, } \\
& \text { o estresse prejudicam a saúde do tra- } \\
& \text { balhador?". } \\
& \text { Participante 17: "Ah, você fica muito agres- } \\
& \text { sivo, arrogante, fica arrogante, fica agres- } \\
& \text { sivo, até chega a se desentender com os } \\
& \text { próprios parceiros ... estresse gera violência, } \\
& \text { arrogância, se for arrogante com uma pes- } \\
& \text { soa, o cara vai te estranhar. }
\end{aligned}
$$

Estudos sobre o estresse no trabalho referiram que demandas de natureza psicológica, quantitativas (e.g tempo e velocidade na realização do trabalho) ou qualitativas (e.g conflitos entre demandas contraditórias) e controle do processo de trabalho (uso de habilidades intelectuais no trabalho e autoridade nas decisões sobre a forma de execução do trabalho) podem relacionar-se com a ocorrência de acidentes de trabalho ou ao adoecimento psíquico do trabalhador (Kerry et al., 2012; Nolting, Berger, Schiffhorst, Genz, \& Kodt (2002), Fischer et al., 2005). Esses autores identificaram o efeito da alta demanda e do baixo controle no aumento da ocorrência de acidentes de trabalho. Segundo os autores, essas relações podem, em função do apoio social recebido dos colegas de trabalho ou chefes, ser amenizadas (maior apoio) ou potencializadas (menor apoio).

Com relação ao universo dos trabalhadores portuários avulsos, pode-se aferir a existência de demanda por habilidades cognitivas e emocionais complexas (e.g exigência de alta produtividade e atenção, manejo de conflito entre trabalhadores). Além disso, há baixo controle no processo de trabalho (operações fragmentadas, falta de uma liderança treinada em cada equipe para tomar decisões, falta de comunicação com os empregadores), quadro esse que pode explicar o grande número de acidentes que ocorrem cotidianamente no setor.

\section{Desempenho no Inventário de Sintomas de Stress para Adultos}

A Tabela 2 apresenta o desempenho dos trabalhadores entrevistados por categoria funcional no ISSL (Lipp, 2000). 
Tabela 2

Desempenho dos trabalhadores entrevistados, por categoria funcional, no Inventário de Sintomas de Stress para Adultos de Lipp (ISSL)

\begin{tabular}{lccccc}
\hline \multirow{2}{*}{ ISSL } & \multicolumn{5}{c}{ Categoria funcional } \\
\cline { 2 - 6 } & Estiva & Capatazia & Conferente & Vigia & Total \\
\hline Sem estresse & 4 & 1 & 2 & 0 & 7 \\
Fase de estresse & & & & & \\
Alerta & 0 & 0 & 0 & 1 & 1 \\
Resistência & 6 & 1 & 0 & 0 & 7 \\
Quase-exaustão & 1 & 1 & 0 & 0 & 2 \\
Exaustão & 0 & 0 & 0 & 0 & 0 \\
Sintomatologia & & & & & \\
Físico & 4 & 0 & 0 & 0 & 4 \\
Psicológico & 2 & 3 & 0 & 0 & 5 \\
Físico e psicológico & 1 & 0 & 0 & 0 & 1 \\
\hline
\end{tabular}

Nove participantes apresentaram estresse em níveis considerados patológicos, sendo sete na fase de resistência (seis, estiva; um, capatazia) e dois na fase de quase-exaustão (um, estiva; um, capatazia). Apenas um apresentou estresse considerado positivo, na fase de alerta (um vigia).

Quanto à sintomatologia, dos 10 participantes com estresse, 5 apresentaram predominância de sintomas psicológicos (2, estiva; 3, capatazia); quatro, físicos (estiva); e 1, físico e psicológico (estiva). Os dados permitem identificar que as únicas categorias funcionais - estiva e capatazia -, caracterizadas por menor remuneração e atividade tipicamente braçal (movimentação de mercadoria nos conveses, nos porões das embarcações ou nos espaços públicos) apresentaram sintomas de estresse patológico (fase de resistência e quase-exaustão). Por outro lado, os conferentes, responsáveis pela checagem das mercadorias e que têm melhor remuneração, não apresentaram estresse. Fonseca, Blank, Barros, \& Nahas (2008), ao comparar trabalhadores da indústria que apresentavam renda mais elevada com os de menor renda, encontraram entre estes últimos (e que exerciam atividades físicas intensas) maior percepção negativa das condições de saúde, as quais estiveram associadas ao estresse percebido.

A predominância de estresse na fase de resistência foi observada em outros estudos. Dentre

514 eles, destacam-se os trabalhos de Almondes e
Araújo (2009), que avaliaram trabalhadores de diferentes turnos; Costa, Accioly, Oliveira e Maia (2007), com estudo sobre policiais militares na cidade de Natal (RN), Brasil; e de Santos e Cardoso (2010), em investigação sobre profissionais de saúde mental de uma cidade no interior do estado de São Paulo.

É importante afirmar que não foram encontrados estudos relacionando estresse especificamente ao trabalho portuário. No entanto, apesar de não se tratar da mesma população da amostra, tal achado evidencia consistência dos dados do presente estudo, em relação a trabalhos realizados com outras populações. Os resultados indicaram ainda que, dentre os participantes com níveis clínicos de estresse, houve maior manifestação de sintomas psicológicos (50\%), seguidos dos físicos (40\%) e dos dois, concomitantemente (10\%).

Adicionalmente, um estudo que avaliou, entre outras variáveis, os níveis de estresse profissional e agentes estressores relacionados ao trabalho entre oficiais de polícia seniores brasileiros $(N=418)$, revelou que estes percebem a profissão como muito estressante, com $43 \%$ deles apresentando sintomas significativos de estresse. Os dados do estudo mostraram haver relação entre estresse e baixa qualidade de vida, bem como que $7 \%$ faziam uso de substâncias psicoativas como estratégia de enfrentamento do estresse (Lipp, 2009). Entende-se que a população estudada pela autora apresenta semelhanças importantes com o presente estudo, como níveis elevados de estresse e conflitos entre os trabalhadores.

\section{Considerações Finais}

As relações estabelecidas no período anterior à modernização portuária promoviam, para os TPA, controle sobre o mercado e o processo de trabalho, assim como reforçavam o sentimento de pertencimento em relação à administração portuária e moldavam suas ações no enfrentamento das contingências do trabalho cotidiano. Portanto, tais relações pareciam funcionar como fatores de proteção em relação ao estresse ocupacional e favoreciam a 
emergência de respostas emocionais relacionadas à satisfação, segurança e bem-estar. Por outro lado, os TPA referiram não existir, atualmente, controle sobre o processo de trabalho, fato esse que pode aumentar o risco de estresse patológico. Ressalta-se que, com a modernização dos portos e a inserção do Porto de Santos na economia globalizada, o contexto de trabalho atual tornou-se menos tradicional, sendo mais técnico e profissional. Tal característica acompanha exigências de maior segurança no trabalho, aumento de produtividade, maior agilidade no embarque e desembarque, e diminuição de custos operacionais.

No entanto, os relatos dos TPA permitem concluir que o processo de modernização promoveu muitas mudanças que trouxeram impactos negativos na vida do trabalhador portuário. Entre elas, destacam-se: estresse físico e/ou psicológico, pela presença constante de sobrecarga física; exposição a ambientes hostis; má relação com o empregador; falta de entrosamento na equipe de trabalho; diminuição do número de trabalhadores por terno; falta de equidade na distribuição do trabalho; redução da autonomia no trabalho; diminuição da remuneração; diminuição da possibilidade de convívio familiar e de lazer. Tais achados são preocupantes e merecem uma reflexão cuidadosa dos órgãos gestores, reforçando a necessidade de realização de pesquisas sobre trabalhadores portuários.

Exemplo da aproximação de um centro de pesquisa ao ambiente de trabalho portuário é a experiência que vem sendo realizada no Porto de Hamburg, na Alemanha. A parceira entre o departamento de pesquisa e o centro de saúde portuário tem-se revelado uma possibilidade promissora para melhorar as condições de trabalho e de saúde do trabalhador portuário.

Apesar de se caracterizar historicamente como intrínseca ao trabalho portuário, a sazonalidade do trabalho ainda é vista como um fator estressor. Esse fator, somado à forma de seleção e à remuneração por produtividade, exige a presença constante do TPA no local de recrutamento - dada ainda a necessidade de ele fazer mais de uma jornada, por não saber quando haverá trabalho novamente.
Os resultados deste estudo permitiram identificar a presença de estressores físicos (ruídos intensos, chuva, frio, horas prolongadas de trabalho) e psíquicos (mudanças decorrentes do processo de modernização portuária, imprevisibilidade do horário de trabalho, baixa remuneração) expressivos e de grande impacto para a saúde do trabalhador.

Como limitação do estudo, entende-se que não é possível inferir uma relação de causalidade entre as variáveis analisadas, justamente pelas características de um estudo transversal, exploratório e qualitativo. Sugere-se que pesquisas posteriores aprofundem o tema proposto, esperando-se que as reflexões e as questões abertas no presente estudo favoreçam o desenvolvimento de novos achados relativos aos temas estresse, relações trabalhistas e trabalho portuário.

\section{Referências}

Aguiar, M. A. F., Junqueira, L. A. P., \& Freddo, A. C. M. (2006). O sindicato dos estivadores do Porto de Santos e o processo de modernização portuária. Revista de Administração Pública, 40(6), 997-1017.

Almondes, K. M., \& Araújo, J. F. (2009). The impact of different shift work schedules on the levels of anxiety and stress in workers in a petrochemicals company. Estudos de Psicologia (Campinas), 26(1), 15-23. doi: 10.1590/S0103-166X2009000100002

Antoniazzi, A. S., Dell'Aglio, D. D., \& Bandeira, D. R. (1998). O conceito de coping: uma revisão teórica. Estudos de Psicologia, 3(2), 273-294. doi: 10.1590/S0 103-166X2011000200004

Barbosa, S. C., \& Borges, L. O. (2011). Saúde mental e diferentes horários de trabalho para operadores de petróleo. Estudos de Psicologia (Campinas), 28(2), 163-173. doi: 10.1590/S0103-166X2011000200004

Brasil. Presidência da República. (1993). Lei n 8.630, de 25 de fevereiro de 1993. Dispõe sobre o regime jurídico da exploração dos portos organizados e das instalações portuárias e dá outras providências. Diário Oficial da República Federativa do Brasil.

Costa, M., Accioly, H., Jr., Oliveira, J., \& Maia, E. (2007). Estresse: diagnóstico dos policiais militares em uma cidade brasileira. Revista Panamericana de Salud Publica, 21(4), 217-22.

Diéguez, C.R.M.A. (2007). De OGMO (Operário Gestor de Mão-de-Obra) para OGMO (Órgão Gestor de Mão-de-Obra): modernização e cultura do trabalho 
no Porto de Santos (Dissertação de mestrado não-publicada). Universidade de São Paulo.

Dextras-Gauthier, J., Marchand, A., \& Haines, V. (2012). Organizational culture, work organization conditions, and mental health: A proposed integration. International Journal of Stress Management, 19(2), 81-104. Retrieved November 7, 2012, from http:// psycnet.apa.org/journals/str/19/2/81.pdf

Fischer, F. M., Oliveira, D. C., Nagai, R., Teixeira, L. R., Lombardi Jr., M., Latorre, M. R. D. O., \& Cooper, S. P. (2005). Job control, job demands, social support at work and health among adolescent workers. Revista de Saúde Pública, 39(2), 245-253.

Fonseca, S. A., Blank, V. L. G., Barros, M. V. G., \& Nahas M. V. (2008). Percepção de saúde e fatores associados em industriários de Santa Catarina, Brasil. Cadernos de Saúde Pública, 24(3), 567-576.

Gitahy, M. L. C. (1992). Ventos do mar: trabalhadores do porto, movimento operário e cultura urbana em Santos, 1889-1914. São Paulo: Unesp.

Gomes, J. C., \& Junqueira, L. A. P. (2008). Cultura e transformação do trabalho no porto de Santos. Revista de Administração Pública, 42(6), 1095-1119.

Gonçalves, A., \& Nunes, L. A. P. (2008). O grande porto: a modernização no porto de Santos. Santos: Realejo.

Kerry, J., Roman, P., Critchley, J. A., \& Clare, B. (2012). Flexible working conditions and their effects on employee health and wellbeing. Cochrane Database of Systematic Reviews, 10. Retrieved November 12, 2012, from http://cochrane.bvsalud.org/cochrane/ main.php?lib=COC\&searchExp=Workplace $\% 20$ and $\% 20$ Shift\%20and\%20Work\% 20and\%20health\&lang=pt

Kyrou, I., \& Tsigos, C. (2009). Stress hormones: Physiological stress and regulation of metabolism. Current Opinion in Pharmacology, 9(6), 783-793.

Lazarus, R.S. (1999). Stress and emotion. New York: Springer.

Lazarus, R. S., \& Folkman, S. (1984). Stress, appraisal, and coping. New York: Springer.

Leka, S., Griffiths, A., \& Cox, T. (2005). Work organization and stress: Systematic problem approaches for employers, managers and trade union representatives. Geneva: WHO.

Lipp, M. E. N. (2000). Manual do inventário de sintomas de stress para adultos de Lipp. São Paulo: Casa do Psicólogo.

Lipp, M. E. N. (2001). Estresse emocional: a contribuição de estressores internos e externos. Revista de Psiquiatria Clínica, 28(6), 347-348. Recuperado em novembro 12, 2012, de http://www.hcnet.usp.br/ipq/ revista/vol28/n6/artigos/art347.htm
Lipp, M. E. N. (2003). Mecanismos neuropsicofisiológicos do stress: teoria e aplicações clínicas. São Paulo: Casa do Psicólogo.

Lipp, M. E. N. (2009). Stress and quality of life of senior Brazilian police officers. The Spanish Journal of Psychology, 12(2), 593-603. Retrieved November 12, 2012, from http://www.ucm.es/info/Psi/docs/journal/ v12_n2_2009/art593.pdf

Machin, R., Couto, M. T., \& Rossi, C. C. S. (2009). Representações de trabalhadores portuários de Santos-SP sobre a relação trabalho-saúde. Saúde \& Sociedade, 18(4), 639-651.

Minayo, M. C. S. (1992). O desafio do conhecimento: pesquisa qualitativa em saúde. São Paulo: HucitecAbrasco.

Nolting, H. D., Berger, M. J., Schiffhorst, G., Genz, H. O., \& Kordt, M. (2002). Job strain as a risk factor for occupational accidents among hospital nursing staff. Gesundheitwesen, 64(1), 25-32.

Qureshi, A. U., Shabbir A. A., Hafeez, A., \& Ahmad, T. M. (2010). The effect of consecutive extended duty hours on the cognitive and behavioural performance of paediatric medicine residents. Journal of Pakistan Medical Association, 60(8), 644-649.

Santos, A. F. O., \& Cardoso, C. L. (2010). Profissionais de saúde mental: estresse e estressores ocupacionais em saúde mental. Psicologia em Estudo, 15(2), 245-253.

Sardá, J. J., Jr., Legal, E. J., \& Jablonski S. J., Jr., (2008). Estresse: conceitos, métodos, medidas e possibilidades de intervenção. São Paulo: Casa do Psicólogo.

Silva, F. T. (2003). Operários sem patrões: os trabalhadores da cidade de Santos no entre guerras. Campinas: Unicamp.

Soares, J. F. S., Cezar-Vaz, M. R., Mendoza-Sassi, R. A., Almeida, T. L., Muccillo-Baisch, A. L., Soares, M. C. F., \& Costa, V. Z. (2008). Percepção dos trabalhadores avulsos sobre os riscos ocupacionais no porto do Rio Grande, Rio Grane do Sul, Brasil. Cadernos de Saúde Pública, 24(6), 1251-1259. Recuperado em novembro 12, 2012, de http://www.scielo.br/pdf/csp/v24n6/ 06.pdf

Sprung, J. M., \& Jex, S. M. (2012). Work locus of control as a moderator of the relationship between work stressors and counterproductive work behavior. International Journal of Stress Management, 19(4), 272-291. Retrived November 12, 2012, from http:// psycnet.apa.org/journals/str/19/4/272.pdf

Recebido em: 11/1/2013

Versão final em: 17/6/2013

Aprovado em: 6/9/2013 